研 究

パルス通電加圧一燃焼合成法による Mo-Si 系金属間化合物の作製

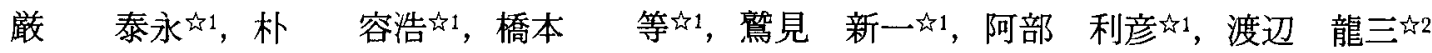

म1 東北工業技術研究所， $\mathbf{T} 983$ 仙台市宮城野区苦竹4-2-1，的 2 東北大学工学部， $\mathbf{T} 980-77$ 仙台市青葉区 荒巻字青葉.

\title{
Fabrication of Mo-Si System Intermetallic Compounds by Pulse Discharge Pressure-Combustion Synthesis
}

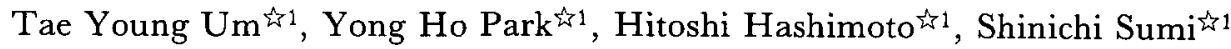

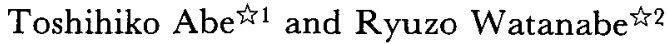 \\ Th1 Tohoku National Industrial Research Institute, 4-2-1 Nigatake Miyagino-ku, Sendai 983. Faculty of \\ Engineering, Tohoku University, Aramaki-aza-aoba Aoba-ku, Sendai 980-77.
}

Received February 12, 1997

\section{SYNOPSIS}

In this study, Mo-Si and Mo-Si-Nb system were fabricated by the pulse discharge pressure-combustion synthesis method ( $\mathrm{Nb}$ was added into $\mathrm{Mo}-\mathrm{Si}$, in order to improve ductility at room temperature and high temperature strength). During the synthesis of Mo-Si and Mo-Si-Nb mixed powders, samples abruptly shrunk at $1323 \mathrm{~K}$. It is clear that combustion reaction occurred at this temperature and compounds were formed by combustion reaction. The relative density of fabricated samples was 96 to $98 \%$ and no internal defects were foundby ultrasound images in the samples. The formed phases of the fabricated samples were as follows;only $\mathrm{MoSi}_{2}$ phases were formed for $\mathrm{Mo}: \mathrm{Si}=1: 2$ mixed powders, and, for the $\mathrm{Nb}$ added samples, $\mathrm{MoSi}_{2}, \mathrm{Nb}_{5} \mathrm{Si}_{3}$ and $\mathrm{Mo}_{5} \mathrm{Si}_{3}$ phases were formed and unreacted $\mathrm{Nb}$ remained. Young's modulus and the bending strength of fabricated samples showed similar results. Monolithic $\mathrm{MoSi}_{2}$ sample had the highest value of Young's modulus and bending strength, and for $\mathrm{Nb}$ added samples, Young's modulus and bending strength decreased with the increase in $\mathrm{Nb}$ content.

\section{KEY WORDS}

pulse discharge pressure-combustion synthesis, Mo-Si, Mo-Si-Nb

\section{1 緒 言}

著者ら ${ }^{1,2)}$ は，緻密な金属間化合物材料を短時間で合 成できる新しいプロセスの開発を目指して，燃焼合成 法とパルス通電加圧焼結法（放電プラズマ焼結法とも 呼ばれる）を組み合わせた「パルス通電加圧一燃焼合成 法」を提案した.この方法は, パルス通電加圧焼結装置 内で燃燒合成反応を起こさせ，合成と同時に焼結繳密 化を行らため，通常の燃焼合成法だけでは得られない 緻密な材料を短時間で合成できるという特徽がある。

著者ら ${ }^{3)}$ は，既にパルス通電加圧－然焼合成法によ る緻密な $\mathrm{Ti}-\mathrm{Al}$ 系金属間化合物の作製について報告し た. 今回は, 高温構造材料として期待されている Mo$\mathrm{Si}$ 系金属間化合物46) と Mo-Si系の室温での延性と高温
強度を改善する目的でNbを添加した Mo-Si-Nb系複合 材料の作製について報告する。

\section{2 試料およひ実験方法}

原料粉末として Mo 粉末（純度 $99.9 \%$ ，平均粒径 $3 \mu \mathrm{m})$, Si 粉末 $(99.9 \%, 10 \mu \mathrm{m})$ および $\mathrm{Nb}$ 粉末 $(99.9 \%$,

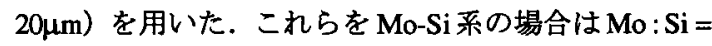
$1: 2$ (モル比) すなわち $\mathrm{MoSi}_{2}$ の組成, Mo-Si-Nb 系の 場合は $\mathrm{MoSi}_{2}$ 組成の $\mathrm{Mo}$ と $\mathrm{Si}$ の混合粉に対して, $\mathrm{Nb}$ 2, 5,8,10wt\%となるように配合した. 粉末の混合条件 の影響を調べるため, ボールミルによる湿式混合 (3h) と 3 次元回転混合機（Turbula）による乾式混合 (24h) の 2 種類を行った. 所定量の混合粉末を内径 $30 \mathrm{~mm}$ の 


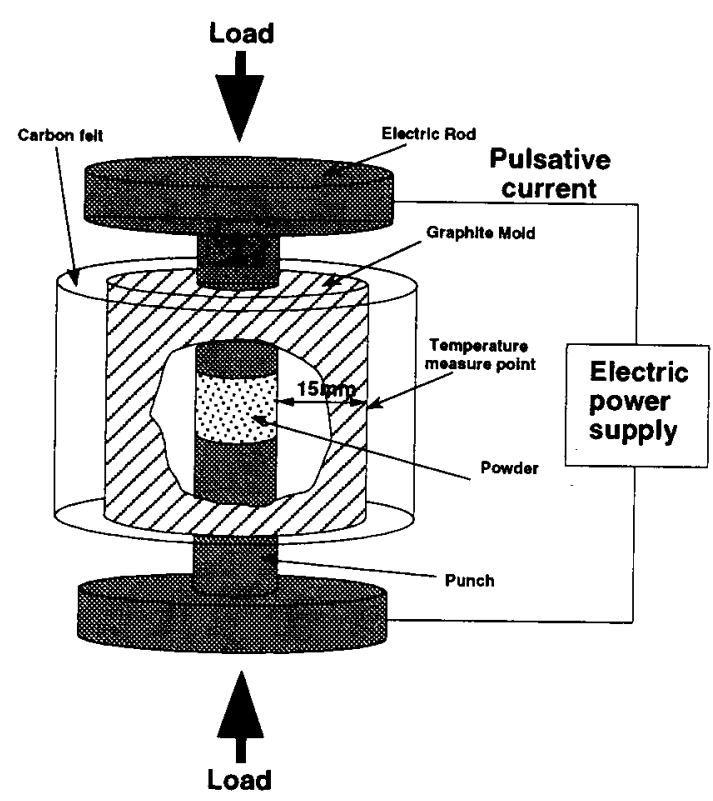

Fig.1 Schematic drawing of mold part in pulse discharge pressure sintering equipment.

円筒形カーボンモールドに充てんし，パルス通電加圧 焼結装置により加圧しながら通電加熱を行った. 概略 を Fig.1に示す. 通電加熱中, 放射温度計を用いてモー ルド表面の温度を測定した（モールド表面から内部の 粉末までの距離は $15 \mathrm{~mm})$. 需囲気は真空 $\left(10^{-3} \mathrm{~Pa}\right)$, 昇 温速度 $1.7 \mathrm{~K} / \mathrm{s}$, 温度 $1673 \mathrm{~K}$, 保持時間 $0.3 \mathrm{Ks}$, 圧力 49MPa とした. なお，モールドには保温のためカーボ ンフェルト製の断熱材を巻いた. 合成した試料につい てアルキメデス法による密度測定, 超音波映像法を用 いた試料内部検查, $\mathrm{X}$ 線回折, 光学顕微鏡による組織 観察, 超音波音速法によるヤング率とポアソン比の測 定および室温における 4 点曲げ試験を行った.

\section{3 実験結果および考察}

Fig.2に, $\mathrm{MoSi}_{2}$ 組成の混合粉をパルス通電加圧焼結 装㯰で通電加熱した場合について，モールド温度と $\mathrm{Z}$ 軸（圧縮軸）変位の通電時閒による変化を示す.ここ で, Z軸変位は試料の収縮量におおよそ対応している。 Z 軸変位すなわち試料の収縮量は通電時間と共に緩や かに增加した後, 急激に増加し, 試料の収縮が急激に 生じていることがわかる。この時のモールド表面温度 は1323Kである.これは，前報3)で詳細に検討したTiAl系と同様に，燃焼合成反応が生じて化合物が形成さ れると共に, 加圧により急激に試料が収縮したものと

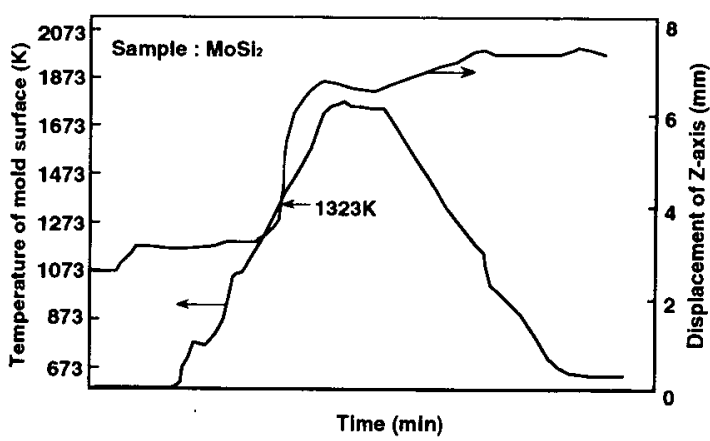

Fig.2 Temperature and Z-axis displacement profiles of Mo: $\mathrm{Si}=1: 2$ mixed powders during the synthesis.

考えられる.ここで, Mo-Si 系の燃焼合成反応を検討 するため, $\mathrm{MoSi}_{2}$ 組成の混合粉を示差走査熱分析装置 により 0.67K/sの昇温速度で1673Kまで加熱した. Fig.3 に, この時のDSC曲線とその微分であるDDSC曲線を 示す. DSC曲線には急激な発熱ピークが見られ，燃焼 合成反応が生じたことが分かる. DDSC 曲線の変曲点 から求めた反応開始温度は $1510 \mathrm{~K}$ である. Mo-Si 系の 状態図をみると，1510K 付近では融点および共晶点等 の変態点はみられない（Si 融点 1687K, 共晶点 1673K） ことから，Ti-Al系では固体の Tiと Al 融液間で燃焼合 成反応が起こるのに対して, Mo-Si系では固体のMoと 固体の Si 間で然焼合成反応が起こるものと考えられ る.また,この温度と Fig.2に示したモールド表面温度 を比較すると，モールド内部の試料の温度とモールド 表面温度の間に約 190Kの差があることがわかる。こ れは，通電による発熱が主に試料粉末で生じており， モールド表面に熱が搪散していることを示すものと考 えられる。

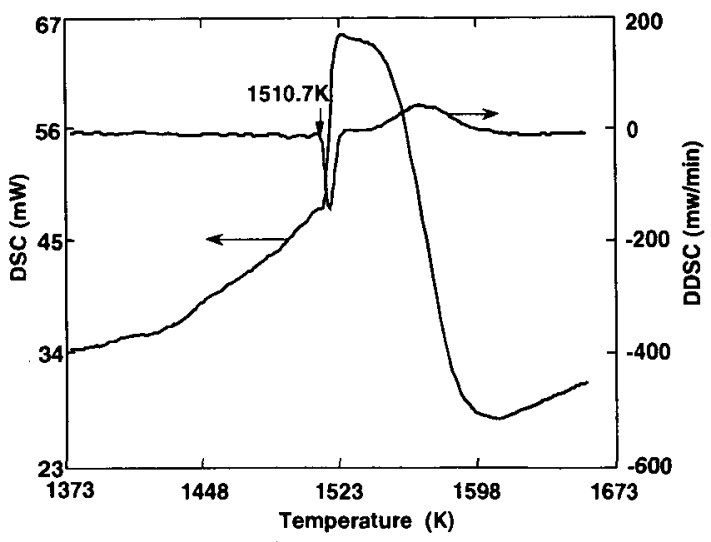

Fig.3 DSC and DDSC profiles of $\mathrm{Mo}: \mathrm{Si}=1: 2$ mixed powder. 


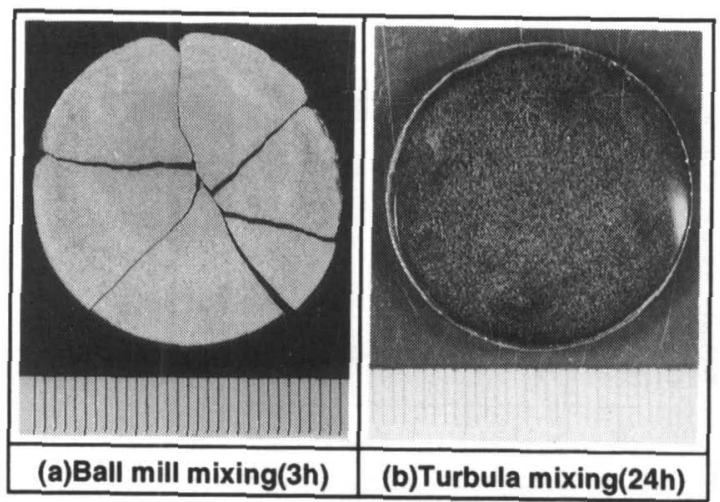

Fig.4 Photographs of $\mathrm{Mo}: \mathrm{Si}=1: 2$ composition samples after synthesis.

前述したように, Mo-Si 系では固体間で燃焼合成反 応が起こると考えられるから，原料粉末の混合状態の 均一性が燃焼合成反応に影響を及ぼすことが予想され る. Fig.4には, ボールミルによる $3 \mathrm{~h}$ の湿式混合を行っ

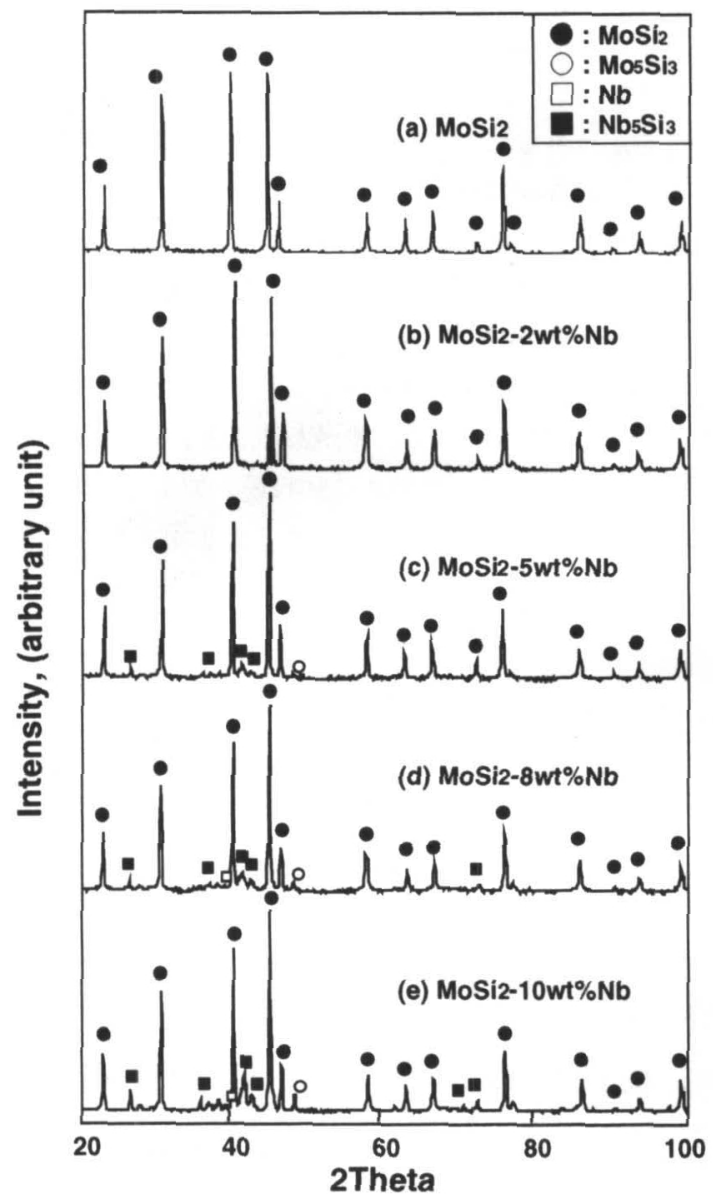

Fig.5 X-ray diffraction profiles of fabricated $\mathrm{MoSi}_{2}$ and $\mathrm{MoSi}_{2}-2,5.8,10 \mathrm{wt} \% \mathrm{Nb}$ samples.
た粉末と Turbulaによる24h の乾式混合を行った粉末 $\left(\mathrm{MoSi}_{2}\right.$ 組成) を用いて合成した試料の外観写真を示 す. $3 \mathrm{~h}$ の湿式混合粉を使った試料は反応中に割れが発 生したのに対して，24h の乾式混合粉を使用した試料 は割れが発生していない. 短時間混合の試料が割れた 原因は，混合が不十分で，反応が試料全体で均一に開 始せず, 反応熱による膨張が不均一に発生して割れが 発生したものと考えられる.この結果から, 固体間で 燃焼合成反応が生じる系では，原料粉末の混合を十分 に行うことが, 割れがない試料を作製する上で重要で あることがわかる。

Fig.5 (a) 〜 (e) に, 合成した各試料のX線回折パター ンを示す. まず, (a) $\mathrm{MoSi}_{2}$ 組成では単相の $\mathrm{MoSi}_{2}$ が合 成されていることがわかる. 一方, $\mathrm{MoSi}_{2}-2 \sim 10 \mathrm{wt} \% \mathrm{Nb}$ 組成では, $\mathrm{MoSi}_{2}$ と末反応の $\mathrm{Nb}$ の他に, 金属間化合物 $\mathrm{Nb}_{5} \mathrm{Si}_{3}$ と $\mathrm{Mo}_{5} \mathrm{Si}_{3}$ が形成されている. 本研究では金属 $\mathrm{Nb}$ の分散による室温延性の改善を目的としているため, $\mathrm{Nb}$ と $\mathrm{Si}$ の反応防止が今後の重要な課題になると考え られる.

Table 1に, アルキメデス法で実測した合成試料の密 度と理論密度に対する相対密度の值をまとめまて示す. 合成した試料は理論密度に対して96〜 98\%の相対密度 を示している. $\mathrm{Nb}_{5} \mathrm{Si}_{3}$ と $\mathrm{Mo}_{5} \mathrm{Si}_{3}$ の形成を考慮すると， 実際の相対密度はさらに減少するものと考えられ, 前 回作製したTi-Al系より緻密化度は低い.Ti-Al系では, Al融液の形成をきっかけに燃焼合成反応が開始するた め, 緻密化が容易であるのに対して, Mo-Si 系は固体 間で反応が起こるため, 繳密化にはより大きな圧力が 必要と考えられる.

Fig.6には, 合成した (a) $\mathrm{MoSi}_{2}$, (b) $\mathrm{MoSi}_{2}-5 \mathrm{wt} \% \mathrm{Nb}$ および (c) $\mathrm{MoSi}_{2}-10 \mathrm{wt} \% \mathrm{Nb}$ 組成の試料の組織を光学顕 微鏡写真で示す. (a) $\mathrm{MoSi}_{2}$ は, $50 \mu \mathrm{m}$ 程度の粗大な 結晶粒の組織であり, 数 $\mu \mathrm{m}$ のポアが試料全体に見ら れる。一方, (b) $\mathrm{MoSi}_{2}-5 \mathrm{wt} \% \mathrm{Nb}$, (c) $\mathrm{MoSi}_{2}-10 \mathrm{wt} \% \mathrm{Nb}$

Table 1 Density and relative density of fabricated $\mathrm{MoSi}_{2}$ and $\mathrm{MoSi}_{2}-2,5.8,10 \mathrm{wt} \% \mathrm{Nb}$ samples.

\begin{tabular}{|l|c|c|}
\hline Composition & Density $\left(\mathrm{g} \cdot \mathrm{cm}^{-3}\right)$ & Relative Density \\
\hline MoSi2 & 6.150 & $98.08 \%$ \\
\hline MoSi2-2wt\%Nb & 6.146 & $97.31 \%$ \\
\hline MoSi2-5wt\%Nb & 6.212 & $97.29 \%$ \\
\hline MoSi2-8wt\%Nb & 6.251 & $96.87 \%$ \\
\hline MoSiz-10wt\%Nb & 6.289 & $96.77 \%$ \\
\hline
\end{tabular}




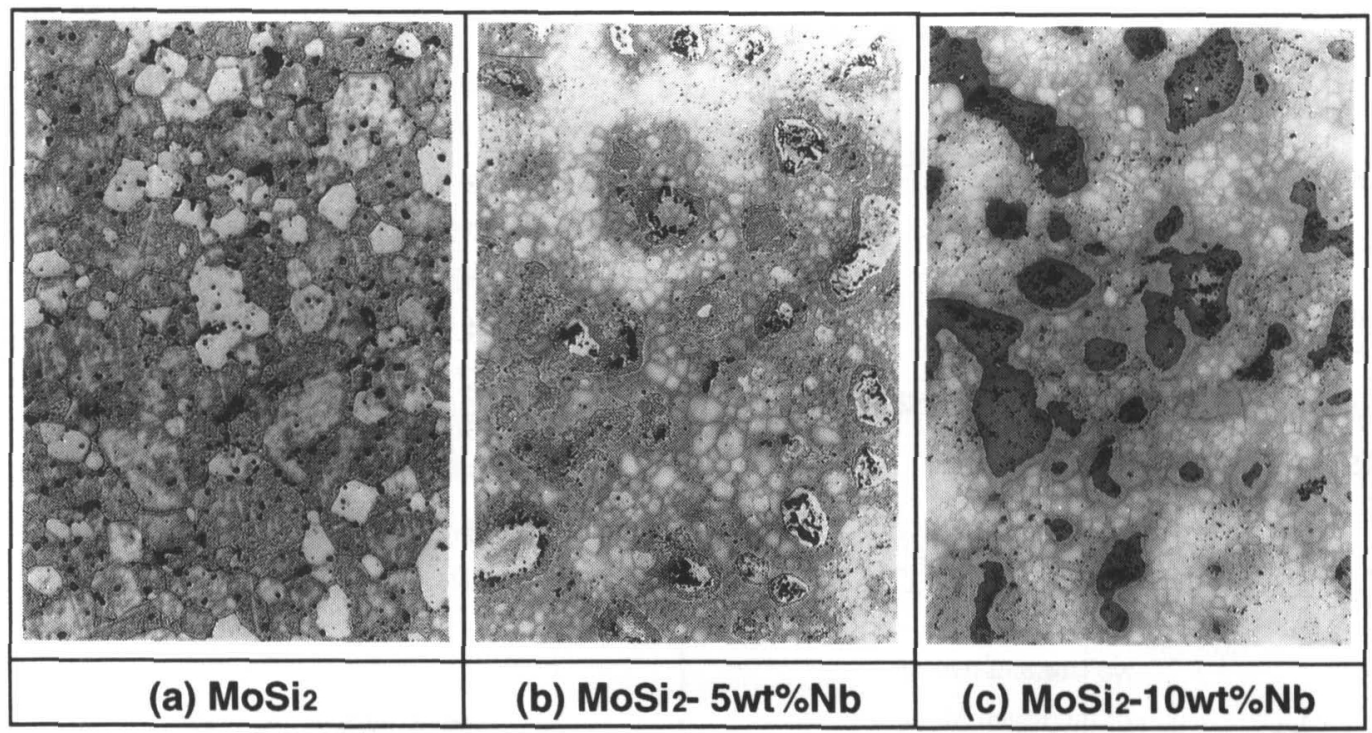

Fig.6 Optical Micrographs of fabricated $\mathrm{MoSi}_{2}$ and $\mathrm{MoSi}_{2}-2,5.8,10 \mathrm{wt} \% \mathrm{Nb}$ samples.

では, $10 \mu \mathrm{m}$ 程度の結晶粒の $\mathrm{MoSi}_{2}$ マトリックス中に $50 \mu \mathrm{m}$ 程度の粗大な $\mathrm{Nb}$ 化合物と思われる粒子が分散 している. X線回折結果から，この粗大な分散粒子は 中心部が $\mathrm{Nb}$ ，周辺部が $\mathrm{Nb}_{5} \mathrm{Si}_{3}$ と思われる.

Fig.7に, $\mathrm{MoSi}_{2}-2,5,8,10 \mathrm{wt} \% \mathrm{Nb}$ の試料の超音波映像 (底面エコー像) を示す. 超音波は, 試料内部のボイド やクラック等の内部欠陥により減衰するため, 内部欠

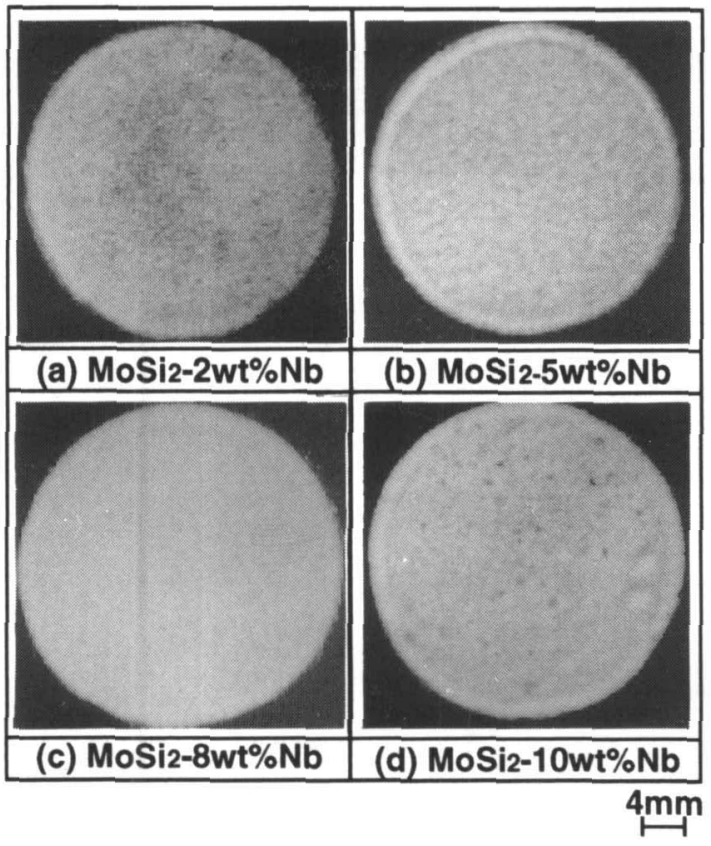

Fig.7 Ultrasonic images of fabricated $\mathrm{MoSi}_{2}-2,5.8,10 \mathrm{wt} \%$ $\mathrm{Nb}$ samples.
陥があると底面エコー像は暗くなる. (a) MoSi $i_{2}$ $2 w t \% \mathrm{Nb}$ の試料に若干のむらが見られるものの, 底面 エコー像がほぼ均一であることから, ボイドやクラッ クなどの内部欠陥はほとんど無いことがわかる.また， 超音波は異種物質界面や結晶粒界によっても減衰する が, 結晶粒径が超音波の波長に比べて短い場合は減衰 が起こらない. $\mathrm{Nb}$ 添加量の増加に伴って底面エコー像 が明るくなるのは, Fig.6の組織写真から分かるよう に, $\mathrm{Nb}$ の添加によって結晶粒径が微細化したためと考 えられる.

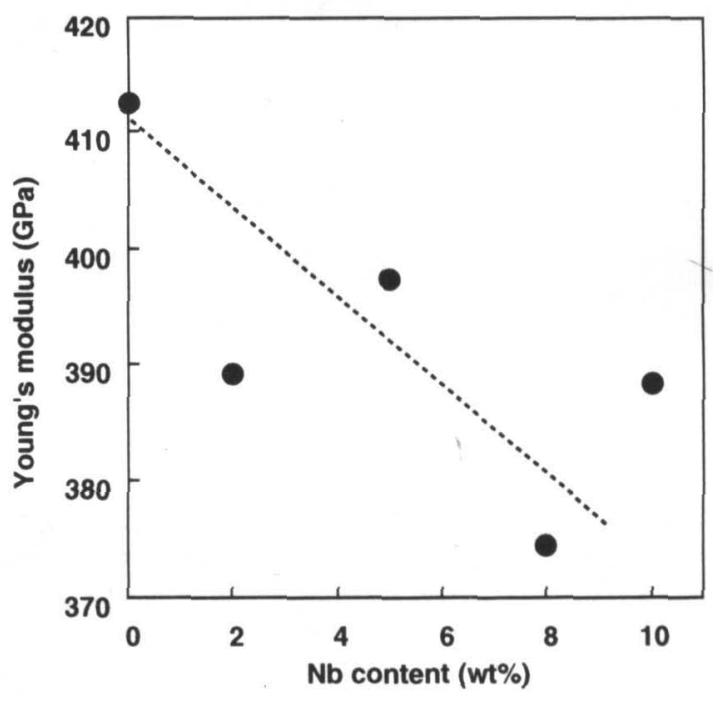

Fig.8 Young's modulus of fabricated $\mathrm{MoSi}_{2}$ and $\mathrm{MoSi}_{2}-2$, $5.8,10 \mathrm{wt} \% \mathrm{Nb}$ samples. 


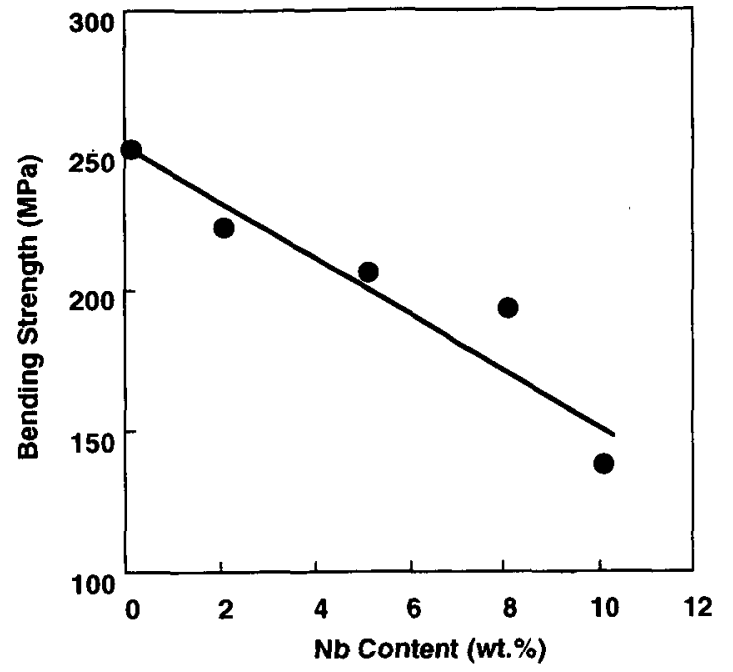

Fig. 9 Bending strength of fabricated $\mathrm{MoSi}_{2}$ and $\mathrm{MoSi}_{2}-2$, $5.8,10 \mathrm{wt} \% \mathrm{Nb}$ samples.

Fig.8に，超音波パルス法（反射法）を用いて測定し た試料のヤング率を原料組成 ( $\mathrm{Nb}$ 添加量) に対してプ ロットした. Nbの添加によって試料のヤング率は減少 する傾向が見られる、また, Fig.9には，室温における 4 点曲げ強度の平均值を原料組成 ( $\mathrm{Nb}$ 添加量) に対し てプロットした. $\mathrm{MoSi}_{2}$ 組成の試料は約 $250 \mathrm{MPa}$ の曲げ 晻度を示すが, $\mathbf{N b}$ の添加量にほぼ比例して低下するこ とがわかる.室温における延性および高温での強度に ついては今後検討する予定である.

\section{4 ま と}

パルス通電加圧－燃燒合成法を用いて, $\mathrm{MoSi}_{2}$ 金属 間化合物および金属 $\mathrm{Nb}$ 分散 $\mathrm{MoSi}_{2}$ 金属間化合物基複 合材料の合成を試み, 以下の結論を得た.

(1) 原料混合粉末をパルス通電加圧中に試料粉末の急激 な収縮が見られた。これから，固体の Moと Si間で然 焼合成反応が生じたものと考えられる.

(2) 合成した試料の形成相は, $\mathrm{MoSi}_{2}$ 組成では $\mathrm{MoSi}_{2}$ 単 相であり，MoSi $\mathrm{Nb}_{5} \mathrm{Si}_{3}$ が形成され, 未反応の $\mathrm{Nb}$ と $\mathrm{Mo}_{5} \mathrm{Si}_{3}$ も検出された.

(3) 合成した試料のヤング率と室温における4 点曲げ强 度は, $\mathrm{Nb}$ 添加量の増加に伴い低下寸る傾向を示した。

\section{文献}

1)撖泰永, 朴容浩, 檑本等, 端見新一，渡辺龍三：日 本金属学会講演概要 (第 115 回), (1994) 350.

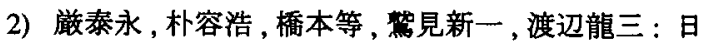
本金属学会講演概要 (第 115 回)，(1996) 275.

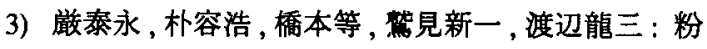
体および粉末治金, 43 (1996) 438.

4) R.K.Wade and J.J.Petrovic: J.Am.Ceram.Soc., 75 (1992) 1682.

5) L.Shaw and R.Abbaschian: J.Am.Ceram.Soc., 76 (1993) 2305.

6) L.Xiao and R.Abbaschian : Metall.Trans.A, 23 (1992) 2863. 